\title{
Safety of Early Oral Feeding After Open Appendicectomy
}

\author{
Sundar Prakash S ${ }^{1}$, Saravanan P S ${ }^{2}$, Alia Hussain ${ }^{3}$, Chandra Prabha ${ }^{4}$ \\ 1. Assistant Professor, Department of General Surgery, Meenakshi Medical College Hospital and Research \\ Institute, Enathur, Kanchipuram. \\ 2. Professor, Department of General Surgery, Meenakshi Medical College Hospital and Research Institute, \\ Enathur, Kanchipuram. \\ 3. Final year Post graduate, Department of General Surgery, Meenakshi Medical College Hospital and \\ Research Institute, Enathur, Kanchipuram. \\ 4. Final year Post graduate, Department of Physiology, Meenakshi Medical College Hospital and Research \\ Institute, Enathur, Kanchipuram.
}

\section{Introduction}

The passage of flatus or bowel movements after abdominal surgery is traditionally considered as the indication for commencing oral diet. The resolution of post-operative ileus defined by the passage of flatus usually occurs after 24 to 48 hours. Hence, patients were started on oral feeding only after the first postoperative day. If studies can prove the safety of early oral feeding after abdominal surgeries, it will help us to reduce the delay in commencing the oral feeding of these patients. Studies were undertaken to evaluate whether different abdominal surgeries could benefit from early oral feeding. Initially, the early oral feeding concept was well established for colorectal surgery. Recently, it has been applied to other abdominal surgeries such as vascular, fundoplication, nephrectomy, appendicectomy, gastric and gynaecological operations. Though we have evidence of safety and advantage of early oral feeding after abdominal surgeries, many surgeons have reservations about this method of early oral feeding due to the fear of the complications such as vomiting, distension, postoperative ileus and anastomotic leak. Appendicectomy is one of the most common surgeries performed by the surgeons worldwide. But, early feeding regimens are not practiced worldwide due to the fear of above stated. Primarily, we undertook a study to evaluate the safety of early oral feeding after open appendicectomy. The secondary purpose of this study was to study the duration of hospital stay in early feeding group in comparison with the traditional feeding group.

\section{Aims And Objectives}

- To evaluate the safety of early oral feeding after open appendicectomy by assessing the incidence of complications such as distension, pain, nausea, vomiting with early feeding in comparison with traditional late feeding.

- To evaluate the duration of hospital stay in patients with early feeding in comparison with traditional late feeding.

\section{Materials And Methods}

This prospective non-blinded randomized, controlled study to evaluate the safety of early oral feeding after open appendicectomy was conducted on 60 patients between January 2012 and June 2013 on patients who underwent open appendicectomy at Meenakshi Medical College Hospital, Kanchipuram. They were divided into two groups: Group A of 30 patients who were started on early feeding and Group B of 30 patients who underwent traditional feeding.

To ensure randomness and eliminate selection bias, cases were selected in a random manner and allotted to either the early feeding or the traditional feeding groups. Epidemiological data of the patients like age, sex, and investigative modalities such as ultrasonographic findings were noted to ensure randomness of the probable confounding factors before statistical analysis.

\section{Inclusion Criteria}

1. All patients with right iliac fossa pain suggestive of appendicitis clinically, complemented by ultrasonography and laboratory investigations.

2. Patients who agreed to participate and those who gave informed consent and complied with the protocol and those who completed full pre-operative workup and subsequently treated with open appendicectomy.

3. Patients aged sixteen years and above. 
4. Patients in whom classical McBurney's or Lanz incision was used.

\section{Exclusion Criteria}

1. Patients unwilling for participation.

2. Patients aged less than sixteen years.

3. Patients in whom pathology other than appendix was found pre-operatively or an additional procedure done with appendicectomy.

4. Patients who were diagnosed to have appendicitis complicated by perforation,abscess, peritonitis or appendicular mass.

5. Patients who required any incision other than a McBurney's or Lanz.

6. Patients who underwent laparoscopic appendicectomy.

7. Patients who were given general anaesthesia.

8. Patients who were lost to follow up.

\section{Methods}

Patients with right iliac fossa pain who consented for the study were enrolled. A detailed history of each patient was recorded. A thorough clinical examination and pre-operative work up was done including laboratory investigations and ultrasonogram. All patients included in the study were treated surgically. Open appendicectomy was done under spinal anaesthesia.

\section{Method of open appendicectomy:}

Under spinal anaesthesia, for all patients, a standard Grid-iron or Lanz incision was made at the McBurney's point. The peritoneum was reached after muscle splitting. Peritoneum was incised and caecum is identified. The appendix was delivered into the wound. The mesoappendix was clamped and ligated. The base of the appendix was ligated and excised. After ensuring hemostasis, wound was closed in layers. If during either of these procedures, other pathologies such as adhesions, cysts, pelvic inflammatory disease etc., were detected or patients, who had appendicular abscess, mass, perforation or required drainage, were excluded from the study.

\section{Post- operative orders:}

Patients in the early feeding group were offered a liquid diet in the ward after the effect of spinal anaesthesia wore off. The liquids were given as and when demanded by the patient. If they were able to tolerate fluid in the first 12 hours, they were started on soft solid diet. Patients in the traditional late feeding group were offered an oral diet after the passage of flatus or bowel sounds.

The patients in both the groups with normal postoperative course were discharged at a time they felt comfortable to return home. The discharge period was thus decided by the patient as per their comfort and not by the attending doctor.They were advised to be reviewed in a week and then after a month unless there were any complications. Sutures will be removed after 8 days.

On each review a repeat analysis of the post-operative pain and incidence of complications were done. All patients of either group while in hospital underwent the following post-operative assessments.

1. Pain score

2. Analgesic use

3. Number of days of hospital stay

4. Complications
a. Vomiting
b. Abdominal distension
c. Wound infection

The assessments were done in the following manner:

\section{1) Pain score:}

\section{Visual Analog Scale (Vas):}

Visual Analogue Scale used was Wong-Baker Faces Pain Rating Scale. It consists of a line of $10 \mathrm{~cm}$ long scale with series of faces ranging from a happy face at 0 -- "No hurt" to a crying face at 10 -- "Hurts worst". The patient must choose the face that best describes how they are feeling. 


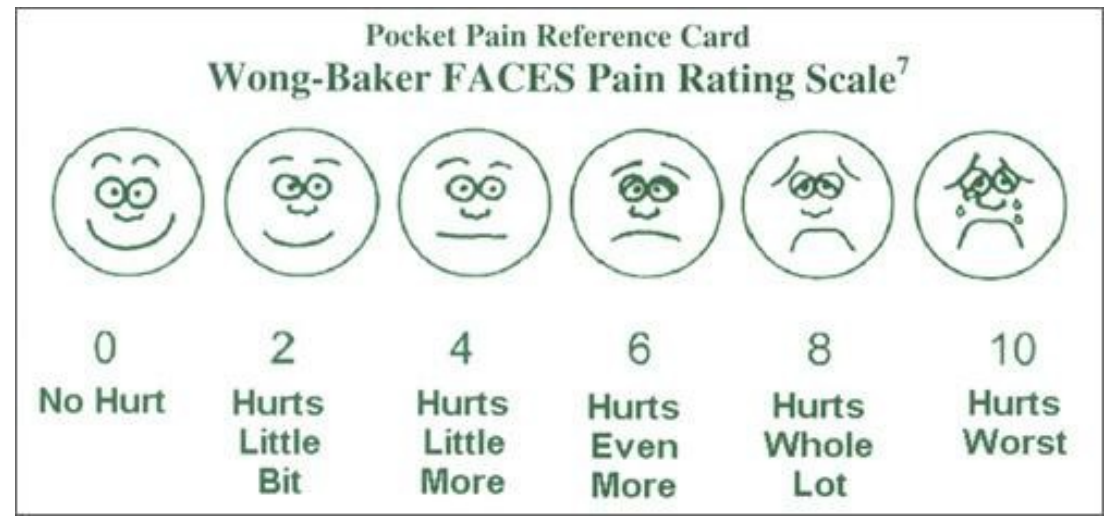

Fig. 28: Wong-Baker FACES pain rating scale

This scale was shown to the patient to measure their postoperative pain on day 1, 2, first follow up (day 8 ), and after 1 month, ensuring that the procedure is well understood by the patient.

On Day-1 - pain was measured after 3 hours of the surgery

On Day-2 - pain was measured in the morning during the postoperative rounds, ensuring that the measurement of pain was not within 6 hours of the analgesic administration as the effect of the analgesic administered would bias the study. Repeat analysis of the score was done on the day of review after a week and after a month.

\section{2) Analgesic use:}

The analgesics were administered postoperatively in both the groups only on demand by the patient and hence the number of days of analgesics used was noted. Each time the patient demanded the analgesics for pain alleviation, 50 milligrams of Diclofenac Sodium was administered intra-muscularly and noted. It was ensured that the maximum dose of $300 \mathrm{mg}$ per day was not exceeded. The average number of days of analgesic requirement of a group during the hospital stay was calculated.

\section{3) Duration of hospital stay:}

This is calculated by the difference in number of days between the date of surgery and the date of discharge at request by the patient when they felt comfortable to return to home.

\section{4) Vomiting:}

If vomiting occurred, the time of occurrence, number of times, the content of vomitus was all noted down. Feeding was stopped and the patient treated with anti-emetics.

\section{5) Distension:}

If distension occurred, the bi-daily abdominal girth chart was maintained and the oral intake was stopped if the patient was on oral diet and the patient monitored closely till distension subsided.

\section{6) Wound complications:}

The post-operative wound complications such as hematoma, seroma or wound infection was observed on day 1, 2, 3, after a week and after a month, unless there were any complications. The patient who returned home earlier, were advised to closely monitor their wounds for any discharge or hematoma. Patients were discharged at request when they felt comfortable to return home. They were advised to be reviewed in a week and then after a month unless there were any complications. On each review, a repeat analysis of the postoperative pain and the incidence of complications were done.

\section{Distribution of sex}

\section{Observations}

Out of 60 patients, 35 patients were males (58\%) and 25 patients were females (42\%).Out of 30 patients in early feeding group, 19 patients were males and 11 patients were females. The male to female ratio was 1.72:1. Out of 30 patients in traditional feeding group, 16 patients were males and 14 patients were females. The male to female ratio was 1.14:1 (Table 1). There was no significant difference between the 2 groups with respect to sex distribution $(\mathrm{P}=0.432)$. 


\begin{tabular}{|l|l|l|l|l|}
\hline Clinical Parameters & Early oral feeding & $\begin{array}{l}\text { Traditional } \\
\text { feeding }\end{array}$ & p value & Significance \\
\hline No. of patients & 30 & 30 & 0.432 & NS \\
Male & 19 & 16 & & \\
Female & 11 & 14 & & \\
M:F ratio & $1.72: 1$ & $1.14: 1$ & NS \\
\hline Mean age (yrs) & 26.27 & 30.8 & 0.537 & \\
\hline
\end{tabular}

Table 1: Comparison of sex and age distribution betweenearly and traditional feeding group

\section{Distribution by Age}

Out of 60 patients, the mean age group was found to be 28.53 years with the commonest age group being between 23-27 years (Table 1).

\section{Distribution of Age with Feeding}

In the early feeding group, the mean age is 26.27 years (Table 1) with the commonest age group being 23 to 27 years. In the traditional feeding group, the mean age is 30.8 years with the commonest age group being 28 to 32 years. There was no significant difference in the age distribution in between the two groups $(\mathrm{p}=0.537)$.

\section{Distribution with Ultrasonographic Findings}

Out of 60 patients, 38 patients were found to have acute appendicitis, 13 patients were found to have sub-acute appendicitis and 9 patients were having chronic appendicitis (Table 2).

\begin{tabular}{|l|l|l|l|}
\hline USG findings & Total no of patients & Early feeding & Traditional feeding \\
\hline Acute appendicitis & 38 & $20(53 \%)$ & $18(47 \%)$ \\
\hline Sub-acute appendicitis & 13 & $5(13 \%)$ & $8(21 \%)$ \\
\hline Chronic appendicitis & 9 & $5(13 \%)$ & $4(11 \%)$ \\
\hline
\end{tabular}

Table 2: USG findings

\section{Distribution of Ultrasonographic Findings with Feeding}

In the ultrasonographic findings of the early feeding group, 20 patients were found to have acute appendicitis, 5 patients were found to have sub-acute appendicitis and 5 patients were found to have chronic appendicitis (Table 2). In the ultrasonographic findings of the traditional feeding group, 18 patients were found to have acute appendicitis, 8 patients were found to have sub-acute appendicitis and 4 patients were found to have chronic appendicitis.

There was no significant difference in the ultrasound findings between the 2 groups $(\mathrm{p}=0.571)$.

\section{Type of Surgery}

Out of 60 patients, 37 (62\%) patients underwent emergency appendicectomy and $23(38 \%)$ patients underwent elective appendicectomy.

\section{Type of Surgery with Feeding}

In the early feeding group, appendicectomy was elective in 11 patients and emergency in 19 patients. In the traditional feeding, group appendicectomy was elective in 12 patients and emergency in 18 patients. There was no significant difference in the type of surgery whether elective or emergency $(p=0.791)$ (Table 3 and Graph 1).

\begin{tabular}{|l|l|l|l|}
\hline Type of surgery & Total no of patients & Early feeding & Traditional feeding \\
\hline Elective appendicectomy & $23(38 \%)$ & $11(48 \%)$ & $12(52 \%)$ \\
\hline Emergency appendicectomy & $37(62 \%)$ & $19(51 \%)$ & $18(49 \%)$ \\
\hline
\end{tabular}

Table 3: Type of surgery 


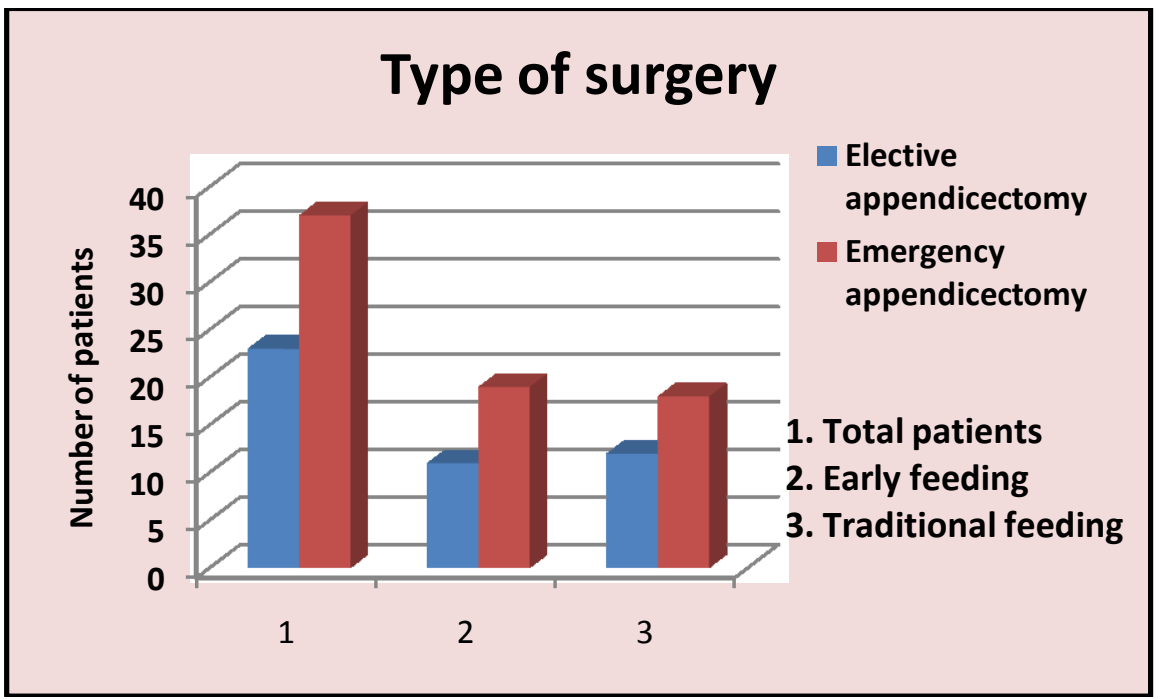

Graph 1: Type of surgery

Post-Operative Assessment Between Early And Traditional Feeding Group

\begin{tabular}{|c|c|c|c|c|c|}
\hline Parameter & & Early oral feeding & $\begin{array}{l}\text { Traditional } \\
\text { feeding }\end{array}$ & P value & Significance \\
\hline \multirow{3}{*}{ Pain Score } & Day 1-2 & 6.75 & 6.75 & 0.514 & NS \\
\hline & 1 week & 0.07 & 0.07 & CONSTANT & NS \\
\hline & 1 month & 0 & 0 & $\mathrm{~T}$ & NS \\
\hline $\begin{array}{l}\text { Analgesic } \\
\text { No. of days }\end{array}$ & & 7.5 & 7.5 & 0.355 & NS \\
\hline \multirow{4}{*}{$\begin{array}{l}\text { Analgesic use in } \\
\text { days }\end{array}$} & 1day & 6 & 3 & & \\
\hline & 2 days & 18 & 16 & & \\
\hline & 3 days & 5 & 7 & & \\
\hline & $>3$ days & 1 & 4 & & \\
\hline \multirow{3}{*}{$\begin{array}{l}\text { Postoperative } \\
\text { complications }\end{array}$} & Vomiting & 2 & 3 & 0.640 & \\
\hline & Distension & 2 & 1 & 0.554 & \\
\hline & Infection & 1 & 1 & 1.000 & \\
\hline $\begin{array}{l}\text { Duration of stay in } \\
\text { hospital }\end{array}$ & & 2.75 & 4.75 & 0.000 & $\mathrm{~S}$ \\
\hline
\end{tabular}

Table 4: Post-operative assessment between early and traditional feeding group

\section{Distribution of Visual Analogue Scale with Feeding}

In the early feeding group, the mean score on day 1 was 7.5 and on day 2 was 6 (mean score for day1, 2 was 6.75). The mean score after 1 week was 0.07 and in the follow up month was found to be 0 . In the traditional group, the mean score on day 1 was 7.5 and on day 2 was 6(mean score for day1, 2 was 6.75 ). The mean score after 1 week was 0.07 and in the follow up month was found to be 0 . p value after day1, day 2,1 week and 1 month was found to be insignificant(Table 4).

\section{Period of Analgesic Use}

Out of 60 patients, 9 patients received analgesics for 1 day; 34 patients received analgesics for 2 days; 12 patients received analgesics for 3 days and 5 patients received analgesics for 4 days.

\section{Period of Analgesic Use with Feeding}

In the early feeding group, 6 patients received analgesics for 1 day; 18 patients received analgesics for 2 days; 5 patients received analgesics for 3 days and 1 patient received analgesics for 4 days. In the traditional feeding group, 3 patients received analgesics for 1 day; 16 patients received analgesics for 2 days; 7 patients received analgesics for 3 days and 4 patients received analgesics for 4 days (Table 4 ). There is no difference in the number of days of analgesics required in the two groups $(p=0.355)$.

\section{Post-Operative Complication of Vomiting with Feeding}

Vomiting occurred in 2 patients in the early feeding group (30 patients) and in patients in the traditional feeding group (30 patients). $(\mathrm{P}=0.640)$ 
Post-operative Complications of Distension with Feeding

Abdominal distension occurred in 2 patients in the early feeding group (30 patients) and in 1 patient in the traditional feeding group (30 patients). $(\mathrm{P}=1.000)$.

\section{Post-Operative Complications of Infection with Feeding}

Wound infection occurred in 1 patient in the early feeding group (30 patients) and in 1 patient in the traditional feeding group (30 patients). $(\mathrm{P}=0.650)$.

\section{Duration of Post-Operative Stay in Hospital}

In the early feeding group the average number of days of hospital stay was 2.75 days and in the traditional group it was 4.75 days. pvalue is significant. $(\mathbf{P}=\mathbf{0 . 0 0 0})$. In the early feeding group the average number of days of hospital stay was less compared to the traditional group (Table4 \& Graph 2).

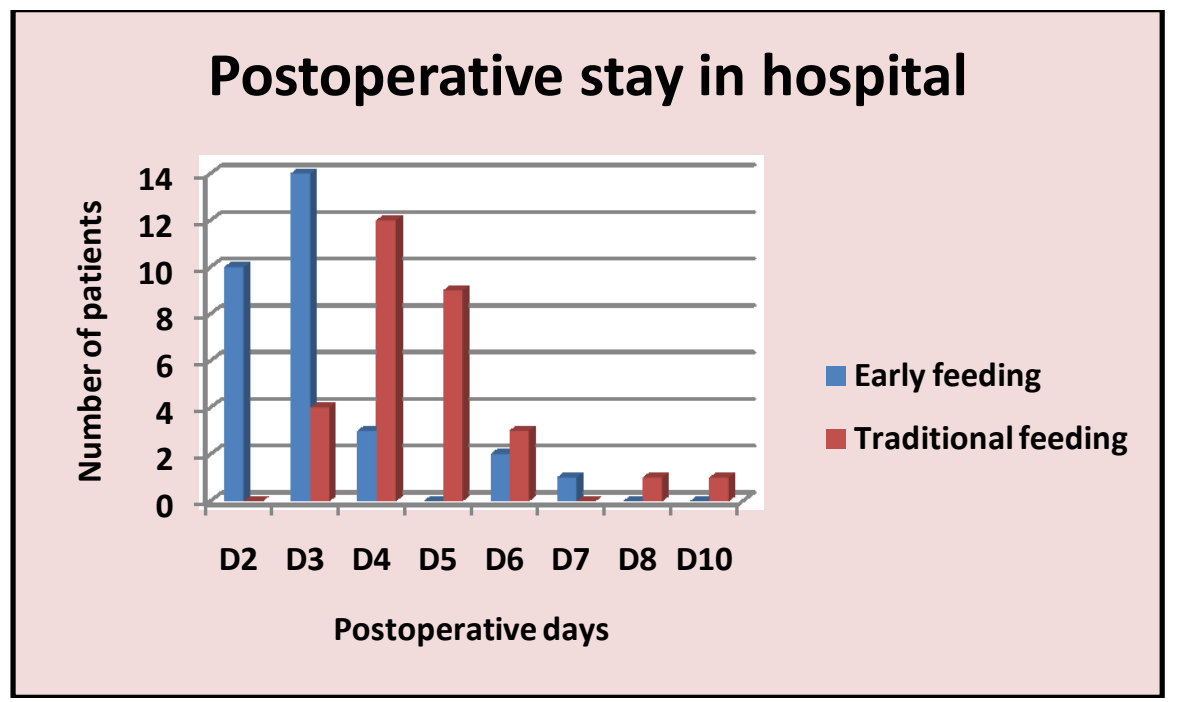

Graph 2: Postoperative stay in the hospital

\section{Discussion}

Traditional care, in which post-operative oral feeding is gradually introduced following the resumption of bowel sounds and the passage of flatus or stools, is based mainly on the apprehension that early oral feeding can cause vomiting and distension, increase anastomotic leakage and prolong paralytic ileus. However, a body of evidence is growing that these apprehensions are without basis and that early oral feeding is not only safe but also offers significant benefits to a patient. Initially, the early oral feeding concept was well established for colorectal surgery. Recently it has been applied to other abdominal surgery, such as vascular, fundoplication, nephrectomy, appendectomy and gynaecological operations.

Current studies indicate that early oral feeding shortens the hospital stay without increasing the morbidity. Although there have been a number of reports on early discharge after open appendectomy in many recent studies, the average post-operative hospital stay after open appendicectomy is reported longer than 48 hours and ranges from 3 to 6 days. Nevertheless, there are very few non-random studies on application of early oral feeding protocols to patients after open appendicectomy. Therefore, we undertook this open, random trial with the primary goal to assess the safety of early feeding in terms of immediate complications. The secondary goal of this study was to record the difference between the duration of hospital stay between the two groups.

In 1995, Seenu and Goel et al showed that early oral feeding after elective colorectal surgery is safe and can be tolerated by most patients.In 1997, Schilder et al showed bowel activity before flatus has passed which illustrates that patients tolerate fluid secretions of $1-2 \mathrm{~L}$ from stomach and pancreas immediately after surgery. In 1998, studies conducted by Bufo et al, Schilder et al, and Reissman et al also have shown tolerance to clear liquids on postoperative day 1 after G.I. surgeries.

In 2001, a meta-analysis conducted by Stephen J Lewis et alon early enteral feeding versus - nil by mouth after gastrointestinal surgery: systematic review and meta-analysis of controlled trials, it was found that early feeding reduced the risk of any type of infection (relative risk $0.72,95 \%$ confidence interval 0.54 to 0.98 , $\mathrm{P}=0.036$ ) and the mean length of stay in hospital (number of days reduced by $0.84,0.36$ to $1.33, \mathrm{P}=0.001$ ). Risk reductions were also seen for anastomotic dehiscence $(0.53,0.26$ to $1.08, \mathrm{P}=0.080)$, wound infection, pneumonia, intra-abdominal abscess, and mortality, but these failed to reach significance $(\mathrm{P}>0.10)$. They 
concluded that there is no clear advantage in keeping patients nil by mouth after gastrointestinal resection and also early feeding patients may benefit from early discharge as well.

In 2001, Marik and Zaloga et al conducted a meta-analysis of prospective, randomized studies comparing early versus late enteral feeding in which they demonstrated the benefits of early nutrition.

In August 2003, Fanaie et al of Baqiyatallah University of medical sciences, Tehran, Iran did a study on the safety of early oral feeding after gastrointestinal anastomosis. They selected 110 patients of which 55 patients were allotted to the early feeding group and 55 patients were allotted to the traditional feeding group. There were no significant demographic differences between the two groups including age, sex, medical and surgical history. Indications for anastomosis were approximately similar between the two groups with biliary tract anastomosis common in the early feeding group ( 8 vs. $7, \mathrm{p}>0.05)$ and small intestinal anastomosis was common in traditional feeding ( 11 vs. $9, \mathrm{p}>0.05)$ and there was no significant difference in the incidence of postoperative complications and pain in between the two groups. Thereby concluding that early enteral feeding in gastro-intestinal anastomosis seemed to be safe, well-tolerated and not associated with increased postoperative gastro-intestinal complications including ileus and post-operative complications such as wound dehiscence, infection, leakage, anastomosis and mortality.

In 2003, Difronzo et al demonstrated a high tolerability (86.5\%) to early postoperative oral feeding after elective open colon resection.

In 2004, Suehiro et al showed that early oral feeding after gastrectomy is safe and the incidence of complications including anastomotic leak and wound infection occurred equally in both groups.

In February 2008, Jerzy kuzma et al of Modilon General Hospital and Faculty of Health Science, Divine Word University, Papua New Guinea did a study on the safety of early oral feeding after open appendicectomy. They selected 62 patients of which 32 patients were allotted to the early feeding group and 30 patients were allotted to the traditional feeding group. Both groups were randomized and there is no significant difference between them in terms of age, sex distribution, lab findings and type of anaesthesia. They found out that there was no significant difference between the two groups in terms of postoperative pain scale, analgesic requirement and complications such as vomiting, abdominal distension, appendiceal stump leak, hematoma and wound infection, but there was significant reduction in the duration of hospital stay in the early feeding group in comparison to the traditional feeding group.

In October 2013, Klappenbach et al conducted a randomized controlled trial on early oral feeding versus traditional postoperative care after abdominal emergency surgery and concluded that early oral feeding was associated with more vomiting which could be treated easily and without patient discomfort and that early oral feeding was safe after abdominal emergency surgery.

In our study between September 2011 to September 2013, 60 patients with right iliac fossa pain and diagnosed as appendicitis were enrolled. 30 patients were started on early oral feeding and the remaining 30 patients were fed traditionally after restoration of bowel functions. This was comparable with the study of Jerzy kuzma et al in which out of the total 62 patients enrolled, 32 patients were started on early feeding and 30 on traditional feeding and also with the study of Fanaie et al in which out of the total 110 patients enrolled, 55 patients were started on early feeding and 55 on traditional feeding. The randomness in our study was achieved by alternate allotment of each patient into either group, whereas Jerzy kuzma et al achieved it by picking lots.

\section{Conclusion}

- Early oral feeding is as safe as traditional feeding.

- There is no significant difference in the post-operative pain, number of days of analgesic requirement, amount of analgesics required between the early feeding and the traditional feeding group.

- There is no significant difference in the post-operative complications such as vomiting, abdominal distension and wound infection between the early feeding group and the traditional feeding group.

- The postoperative hospital stay was less in the early feeding group when compared to the traditional feeding group.

- Early oral feeding is as safe as traditional feeding and has an advantage of lesser hospital stay.

\section{Summary}

The study was conducted on 60 patients who underwent open appendicectomy in Meenakshi Medical College from September 2011 to September 2013.

The aim of the study was to evaluate the safety of early oral feeding after open appendicectomy in comparison with traditional late feeding group and also to evaluate the duration of hospitalisation of patients with early feeding in comparison with traditional late feeding.

The study was conducted by starting early oral feeds on 30 patients and 30 patients were fed traditionally after restoration of bowel functions after satisfying the inclusion and exclusion criteria. 
In this study, appendicitis was more common among the male population with mean age group being between 23-27 years. The most common ultrasound finding was acute appendicitis and the patients were subjected to emergency open appendicectomy.

Post-operatively, there was no significant differentiation in the pain scale or analgesic use or postoperative complications like vomiting, distension or infection. As a consequence, the stay in the hospital was reduced for patients in the early feeding groups.

To summarize, early oral feeding implemented after open appendicectomy is safe because it has not increased the morbidity as compared to the traditional feeding group. Hence, early oral feeding can be commenced after open appendicectomy to benefit the patient both psychologically and financially.

\section{Bibliography}

[1]. Anderson AD, McNaught CE, MacFrie J, Tring I, Barker p, Mitchell CJ. Randomized clinical trial of multimodal optimization and standard perioperative surgical care. Br J Surg 2003; 90:1497e504.

[2]. Basse L, HjortJakobsen D, Billesbolle P, Kehlet H. A clinical pathway to accelerate recovery after colonic resection. Ann Surg 2000; 232(1):51e7.

[3]. Bisgaard T, Kehlet H. Early oral feeding after elective abdominal surgery-what are the issues? Nutrition 2002;18: 944-8.

[4]. Bohm B, Haase O, Hofmann H, Heine G, Junghans T, Muller JM. Tolerance of early

[5]. oral feeding after operation of the lower gastrointestinal tract Chirurg 2000;71:955-62

[6]. Bufo AJ, Feldman S, Daniels GA, Lieberman RC. Early postoperative feeding. Dis Colon Rectum 1994;37:1260-5

[7]. Burrows WR, Gingo AJ Jr, Rose SM, Dierker LJ, et al. Safety and efficacy of early postoperative solid food consumption after cesarian section. J Reported Med 1995;40:463-7.

[8]. Charles V. Mann; The vermiform appendix; In: Bailey \&Love_s short practice of surgery; Charles V. Mann, RCG Russel, Norman S. Williams (Ed); 22nd ed; ELBS; 1995; p 828-40

[9]. Cornelia S Carr, Eddie L, Paul Boulos. Randomized trial of safety and efficacy of immediate postoperative enteral feeding in patients undergoing gastrointestinal resection. BMJ 1996;312:869-71.

[10]. De Aguilar-Nascimento JE, Goelzer J. Early feeding after intestinal anastomosis: risks or benefits? Rev Assoc Med Bras 2002;48:348-52.

[11]. Difronzo LA, Yamin N, Patel K, O'Connel TX. Benefits of early feeding and early hospital discharge in elderly patients undergoing open colon resection. J Am CollSurg 2003;197:747-52.

[12]. Fearon KC, Ljungqvist O, Von Meyenfeldt M, RevhaugA,Dejong CH et al. Enhanced recovery after surgery:a consensus review of clinical care for patients undergoing colonic resection. ClinNutr 2005;24:466e77.

[13]. Feo CV, Romanini B, Sortini D, Ragazzi R, Zamboni P, Pancini GC, et al. Early oral feeding after colorectal resection: a randomized controlled trial.ANZ J Surg 2004;74:296-7

[14]. Finan MA, Barton DP, Fiorica JV, Hoffman MS, Roberts WS, Gleeson N, et al . Ileus following gynecology surgery. South Med J 1995;88:539-42.

[15]. Foulds KA, Beasley SW, Maoate K. Factors that influence length of stay after appendicectomy in children. Aust N Z J Surg 2000;70(1):43e6.

[16]. Grewal H, Sweat J, Vazquez WD. Laparoscopic appendectomy in children can be done as a fast-track or same-day surgery. JSLS 2004;8(2):151e4.

[17]. Han-Geurts IJM, Jeekel J, Tilanus HW, Brouer KJ. Randomized clinical trial of patient-controlled versus fixed regimen feeding after elective abdominal surgery. Br J Surg 2001;85:1578e82.

[18]. Han-Guerts IJM, Hop WCJ, Kok NFM, Brouwer KJ, JeekelJ.Randomized clinical trial of the impact of early enteral feeding on postoperative ileus and recovery. Br J Surg 2007;94:555e61.

[19]. Jakobsen DH, Sonne E, Andreasen J, Kehlet H. Convalescence after colonic surgery with fast-track vs conventional care. Colorectal Dis 2006;8(8):683e7.

[20]. Jerzy KuzmaModilon General Hospital and Faculty of Health Science, Divine Word University, PO Box 483, Madang, Papua New Guinea. Randomized clinical trial to compare the length of hospital stay and morbidity for early feeding with opioid-sparing analgesia versus traditional care after open appendectomy.The journal of European society for clinical nutrition and metabolism (2008) 27, $694-699$.

[21]. Johnson Casto C, Krammer J, Drake J. Postoperative feeding : a clinical review. Obst et GynecolSurv 2000;55:571-3.

[22]. Jones PF. Suspected acute appendicitis: trends in management over 30 years. Br J Surg2001; 88:1570 -1577.

[23]. Klappenbach, Yazyi, Roberto F: Early Oral Feeding Versus Traditional Postoperative Care After Abdominal Emergency Surgery: A Randomized Controlled Trial World Journal of Surgery37.10 (Oct 2013): 2293-2299.

[24]. Kehlet H, Bu"chler MW, BeartJr RW, BillinghamRP,WilliamsonR.Care After colonic e is it evidence-based? Results from a multinational survey in Europe and the United States. J Am CollSurg 2006; 202(1):45e54.

[25]. Livingston EH, Passaro EP Jr, Postoperative ileus. Digest Dis Sci 1990;35:121-32. .

[26]. Marik PE, Zaloga G. Early enteral nutrition in acutely ill patients: a systematic review. Crit care Med 2001;29:2264-70.

[27]. Nicholas J Petrelli, Charles Cheng, Deborah Driscoll. Early Post operative Oral Feeding After Colectomy; An Analysis of Factors That May Predict Failure. Annals of Surgical Oncology 2001;8:796-800

[28]. Pearl ML, Valea FA, Fischer M, Mahler L, Chalas EA. A randomized control trial of early postoperative feeding in gynecologic oncology patients undergoing intra-abdominal surgery.Obst et Gynecol 1998;93:94e7. 99

[29]. Petrelli NJ, Cheng C, Driscoll D, Rodriguez-Bigas MA. Early postoperative oral feeding after colectomy: an analysis of factors that may predict failure. Ann SurgOncol 2001; 8:796-800

[30]. Ramesh S, Galland RB. Early discharge from hospital after open appendicectomy. Br J Surg 1993;80(9):1192e3.

[31]. Reismann M, von Kampen M, Laupichler B, SuempelmannR,Schmidt AI, Ure BM. Fast-track surgery in infants and children. J PediatrSurg 2007;42(1):234e8.

[32]. Reissman P, Teoh TA, Cohen SM, Weiss EG, Nogueras IJ, Wexner SD. Is early oral feeding is safe after elective colorectal surgery? A Prospective randomized trial. Ann Surg 1995; 222:73-7.

[33]. Resnick J, Greenwald DA, Brandt LJ. Dealayed gastric emptying and postoperative ileus after nongastric abdominal surgery: Part 1. AM J Gastroentrol 1997;92:751-62

[34]. Robbins_s\&Cotran Pathologic basis of diseases; Kumar V; Abbas AK; Fausto N (Eds); 7th ed; Elsevier; 2004; 870 
[35]. S.A.Fanaie, S.Ziaee department of surgery Baqiatallah university of medical sciences, Tehran Iran. Safety of early oral feeding after gastrointestinal anastomosis: a randomized clinical trial. Indian Journal of Surgery Vol. 67, No. 4, 2005, pp. 185-188.

[36]. Sanjay Kumar Bhasin et al. "Vermiform Appendix And Acute Appendicitis." JK-Sciences 9.4 (2007): 167-170

[37]. Schilder JM, Hurteau JA, Look KY, Moore DH, Raff G, St ehman FB, et al . A prospective controlled trial of early postoperative oral intake following major abdominal gynecologicsurgery.GynecoloOncol 1997;67:235-40.

[38]. Schroeder D, Gillanders L, Mahr K, Hill GL. Effects of immediate postoperative enteral nutrition on body composition, muscle function and wound healing. J Parenter Enteral Nutr 1991;15:376-83.

[39]. Seenu V, GoelAk. Early feeding after elective colorectal surgery: is it safe. Trop Gastroenterol 1995;16:72-3

[40]. Soop M, Carlson GL, Hopkinson J, Thorell A, NygrenJ,et al. Randomized clinical trial of the effects of immediate enteral nutrition 98 on metabolic responses to major colorectal surgery in an enhanced recovery protocol. Br J Surg 2004;91:1138e45

[41]. Stephen J Lewis et al.Early enteral feeding versus - nil by mouth after gastrointestinal surgery: systematic review and meta-analysis of controlled trials.BMJ2001;723:773.

[42]. Suehiro T, Matasumata T, Shikada Y, Sugimachi K. Accelerated rehabilitation with early postoperative oral feeding following gastrectomy $2004 ; 51: 1852-5$

[43]. ToulsonD.C. ,Maria I da silva, Rodrigo G. The impact of early nutrition on metabolic response and postoperative ileus. Current Opinion in Clinical Nutrition \& Metabolic Care 2004;7:577-83.

[44]. Van Dieijen-Visser MP; Go PM; Brombacher PJ: The value of laboratory tests in patients suspected of Acute appendicitis; EurClinChemBiochem, 1991 Nov; 29(11): 749-52.

[45]. Velhote CE, de Oliveira Velhote TF, Velhote MC, Moura DC. Early discharge after appendicectomy in children.Eur J Surg1999;165(5):465e7.

[46]. Wallbridge PH. Double appendix. Br J Surg 1963;50:346-347. 